difficult to research U.S. regulations. Nevertheless, irrespective of its limited information value, the new 984-page index at U.S. $\$ 8.50$ a copy is still very cheap in this age of high book prices.

HOW ARD A. HOOD

Vanderbilt University

\title{
A NEW NEWSLETTER FOR INTERNATIONAL LAWYERS
}

InTERnational LAWYer's NewsLetter is a new periodical publication which has exchange of information among attorneys with international practices as its primary purpose. Its advisory editorial board includes a member of Baker \& McKenzie, the renowned international law firm, and representatives of several international banks and multinational corporations.

Judging by the content of the first issue, published in late 1979 and containing 18 pages, the InTERnational LAWYER'S NewSLETTER is sufficiently original to become a success among attorneys and executives with international practices. It includes short newsworthy comments on such legal items as usury in the Middle East, taxation, unfair trade practices, etc., as well as some practical advice on international legal procedure, e.g., legalization of documents to be used abroad. But that is not all. Breaking the traditional stuffiness of legal publications, this newsletter also contains practical advice on weekends in Brazil, the purchase of oriental rugs in Istanbul, shopping in Beijing (Peking), job hunting for international law positions, and many other items of everyday interest.

The annual subscription rate is U.S. $\$ 14.00$ in the United States and Canada; U.S. $\$ 16.00$ elsewhere. At such a reasonable rate the temptation to subscribe is strong. For subscriptions write to International Lawyer's Newsletter, 11055 N.W. Ridge Road, Portland, OR 97229, U.S.A. 